\title{
AS FONTES DE INFORMAÇÃO DIGITAIS EM BIBLIOTECAS UNIVERSITÁRIAS: UM ESTUDO A PARTIR DAS UNIVERSIDADES DE CARÁTER PÚBLICO E PRIVADO DO ESPÍRITO SANTO (ES)
}

\author{
Daire Strite de Azevedo Cerqueira \\ Bacharel em Biblioteconomia \\ daire_strit@yahoo.com.br \\ Ricardo Soares do Nascimento \\ Bacharel em Biblioteconomia \\ ricardossn79@yahoo.com.br \\ Marta Leandro da Mata \\ Professora do Departamento de Biblioteconomia - UFES \\ Doutora em Ciência da Informação \\ martaleandrodamata@gmail.com
}

Resumo

As bibliotecas universitárias têm procurado acompanhar as inovações para facilitar o acesso à informação aos seus usuários, oferecendo diversos recursos, produtos e serviços, incluindo as fontes de informação digitais. Neste sentido, este estudo teve como objetivo investigar as fontes de informação digitais, com ênfase nas bases de dados e $e$-books, disponibilizados aos usuários de duas bibliotecas universitárias, públicas e privadas, do Estado do Espírito Santo (ES). Tendo-se como objetivos específicos identificar os recursos digitais adquiridos pelas bibliotecas; verificar a forma de disponibilização; verificar se possui atividades de capacitação de usuários para o seu uso, mostrando possíveis diferenças entre estas as bibliotecas. Para tanto, realizou-se uma pesquisa exploratória e com análise qualitativa dos resultados. Os resultados mostram que essas bibliotecas vêm adquirindo fontes de informação digitais para disponibilizar a comunidade acadêmica. Entretanto, existem poucos recursos direcionados aos e-books. São realizadas atividades de formação de usuários, que contribuir para a promoção e uso de tais fontes.

Palavras-chave: Biblioteca universitária. Fontes de informação digitais. Base de dados. E-books.

\section{INTRODUÇÃO}

No meio acadêmico, a produção de informação científica faz parte da vida dos estudantes, nos níveis de graduação, mestrado e/ou doutorado, bem como dos professores e pesquisadores. Ter acesso às fontes de informação relevantes e com qualidade é imprescindível para desenvolver as atividades de ensino, pesquisa e extensão, que constituem o tripé da universidade brasileira. Ressalta-se que "[...] a educação superior e a pesquisa atuam agora como componentes essenciais do desenvolvimento cultural e socioeconômico de indivíduos, comunidades e nações" (UNESCO, 1998, p. 12).

Neste contexto, o uso de fontes de informações digitais tem crescido gradualmente, no decorrer dos anos, por parte dos universitários, com intuito de realizar suas atividades acadêmicas. Silveira (2008) constata essa afirmação ao realizar uma análise dos artigos publicados no periódico "Ciência da Informação". Entre tais motivos para esse aumento, destaca-se a questão da rapidez no acesso às fontes e a transposição das barreiras geográficas.

Para Silva e Tomaél (2004), na internet é possível encontrar variadas tipologias de fontes de informação, desde fontes convencionais até aquelas pouco exploradas, sendo que algumas nem sempre possuem relevância e qualidade. Conforme Miranda (2007, p. 3), para que a informação tenha qualidade é necessário que "[...] seja relevante, confiável, atual, acessível, precisa, oportuna e deve ser ajustada às demandas e expectativas dos usuários. $\mathrm{O}$ valor da 
informação está associado à utilidade que ela apresenta para o público a quem se destina".

As bibliotecas universitárias (BU) têm procurado acompanhar essas inovações, de modo a propiciar a disseminação, o acesso e o uso da informação aos seus usuários, oferecendo diversos recursos, produtos e serviços, incluindo as fontes de informação digitais, tais como as bases de dados e, recentemente, os e-books. A BU é um espaço de difusão do conhecimento por excelência, que auxilia a universidade a alcançar seus objetivos, servindo de apoio no âmbito científico, tecnológico, social e cultural (NUNES; CARVALHO, 2016). As autoras ressaltam que

A atuação das bibliotecas universitárias, dentro da perspectiva global, envolve a difusão do conhecimento com a aplicação de recursos humanos e materiais na perspectiva da criação de redes de informação, da formação de competências em informação, e da construção do protagonismo social dos indivíduos (NUNES; CARVALHO, 2016, p. 191).

Neste sentido, o presente estudo teve como objetivo analisar as fontes de informação digitais disponibilizados aos usuários de duas bibliotecas universitárias, do Estado do Espírito Santo (ES), uma de caráter público e outra de caráter privado. Tendo-se como objetivos específicos identificar as fontes de informação digitais disponíveis pelas bibliotecas; verificar a forma de disponibilizado dessas fontes para a comunidade acadêmica de cada instituição; verificar se possui algum programa de formação para desenvolver habilidades informacionais nos indivíduos. A partir de tais análises é possível mostrar possíveis diferenças existentes entre estes ambientes institucionais públicos e privados do estado.

O Estado do Espírito Santo (ES) possui duas instituições de ensino superior compreendidas como universidades (IES), conforme as "Diretrizes e Bases da Educação Nacional" (BRASIL, 1996), sendo uma de caráter público e outra privada. As BU delimitadas para o universo desta pesquisa são partes integrantes destas instituições. Essas IES contribuem para o desenvolvimento de recursos humanos, profissionais e científicos, bem como para o desenvolvimento educacional do Estado.

\section{FONTES DE INFORMAÇÃO NO AMBIENTE ACADÊMICO}

Os meios utilizados para transmissão de mensagens desde a descoberta da escrita mudaram ao longo da história, desde os registros nas cavernas até os meios de comunicação contemporâneos. Atualmente, com a popularização dos computadores e da internet, torna-se necessário e, inevitável, o uso do suporte digital para a produção, disseminação e uso das informações.

No que tange aos materiais obtidos pelas unidades de informação, tornou-se possível adquirir novos tipos de recursos e fontes, que variam em seu formato e meio de divulgação. Referentes às atividades do bibliotecário, as tecnologias trouxeram modernas ferramentas para auxiliar na organização, tratamento e disseminação de informações, destacando-se que seu trabalho "[...] é, em grande parte, baseado no conhecimento e uso de fontes de informação sobre a literatura científica" (MUELLER, 2007, p. 23).

Souto (2010, p. 12), considera que "os recursos informacionais, em um aspecto amplo, referem-se às fontes de informação científicas, técnicas e/ou informais, podendo incluir indivíduos, entendendo-os também como fontes de informação". No que se refere ao conceito de fontes de informação, Cunha (2001), afirma é muito amplo e envolve os mais diversos tipos de materiais. De modo geral, as fontes de informação abrangem vários tipos de itens/documentos, que estejam em diversos suportes e formatos (impressos, eletrônicos, imagens e/ou áudio), podendo inclusive ser uma pessoa ou uma instituição, tendo a finalidade de disseminar, transmitir e atender necessidades informacionais dos indivíduos.

Existem as fontes de informação gerais e as especializadas. Estas últimas adéquam-se melhor ao contexto deste estudo, visto tratar-se de fontes destinadas aos estudantes de graduação e pósgraduação, bem como aos professores e pesquisadores.

Faz-se necessário mencionar que as informações, principalmente, aquelas de caráter científico podem ser divulgadas por meio de canais de comunicação informais e formais. Nos primeiros, os canais informais, podem estar inclusas comunicações de caráter mais pessoal ou que se referem à pesquisa ainda não concluída, como comunicação de pesquisa em andamento, certos trabalhos de congressos e 
outras com características semelhantes. No segundo, os canais formais, estão inclusas, geralmente, as publicações com divulgação mais ampla, como periódicos e livros (MUELLER, 2007). As fontes de informação podem ser classificadas em primárias, secundárias e terciárias, conforme Mueller (2007) e Cunha (2001).

As fontes ou documentos primários “[...] são geralmente aqueles produzidos com a interferência direta do autor da pesquisa" (MUELLER, 2007, p. 31), alguns exemplos são os artigos de periódicos científicos, anais de conferência, monografias, dissertações e teses e relatórios técnicos. As fontes secundárias têm a função de auxiliar no uso do conhecimento contido nas fontes primárias. Como por exemplo, enciclopédias, dicionários, manuais, tabelas, revisões da literatura, tratados, certas monografias e livros-texto, anuários, etc. As terciárias, segundo Mueller (2007, p. 31), “[...] são aquelas que têm a função de guiar o usuário para as fontes primárias e secundárias", por exemplo: as bases de dados, os diretórios, entre outros.

Tais fontes podem ser publicadas em formato impresso e/ou digital. De acordo com Almeida (2004, p. 57), "As informações contidas na rede podem ser igualmente utilizadas como fontes de informação. Por dar possibilidade de integrar várias mídias, a Internet tornou viável a disposição das tradicionais fontes de informação". De modo complementar Rodrigues e Blattmann (2011, p. 48) apontam que:

[...] recentemente, verificou-se uma mudança na percepção das fontes de informação. Até fins dos anos de 1990, fontes de informação eram sinônimos de formato impresso. Com a disseminação das tecnologias de informação e comunicação e o uso intensivo da Internet, fontes de informação passaram a ser sinônimo de recursos informacionais disponíveis no formato digital.

O bibliotecário deve possuir competências para lidar com as informações alocadas no ambiente da web, porquanto, cada vez mais a internet tem se tornado uma fonte de busca de informação importante e utilizada. Conforme Rodrigues e Balttmann (2011, p. 49), "Com o aumento do número de usuários, serviços e acessos à Internet, o ambiente digital torna-se uma indispensável ferramenta de acesso às fontes de informação." Porém, nem todas as informações que estão disponíveis neste meio possuem qualidade, nem são pertinentes e com credibilidade para uso no contexto acadêmico.

Definir a qualidade de uma informação é algo que requer bastante cuidado e afinco, pois "a qualidade de uma informação ou de uma fonte de informação está diretamente relacionada ao seu uso, ou seja, ao usuário que dela necessita", (ALCARÁ; SILVA; TOMAEL, 2008, p. 7). Cabe, também, ao bibliotecário usar critérios para avaliar a sua qualidade.

Neste sentido, ter conhecimento acerca das fontes de informação é fundamental para tal profissional, de modo que possa gerenciá-la e divulgá-la aos usuários/indivíduos de forma eficiente. Blattmann e Rodrigues (2011, p. 48) afirmam que "Nos estudos sobre fontes de informação, percebe-se que o desafio das pessoas, instituições e empresas está em organizá-las sistematicamente para possibilitar o acesso a essas informações e seu uso adequado".

Os bibliotecários, que atuam em bibliotecas universitárias, devem conhecer as fontes de informação e sua tipologia, os canais de comunicação e divulgação que percorre, interna e externamente, possibilitando acesso ao conhecimento registrado em diversos meios, de modo que realizem a mediação entre a informação e os usuários, visando que este consiga a informação desejada. Dias et al. (2004, p. 2) afirma que:

[...] os bibliotecários devem ter habilidades especiais em relação ao ensino/aprendizagem da localização de recursos, a formulação adequada das buscas, a decodificação da informação, a localização, a seleção e consulta de registros e de documentos em diferentes suportes e formatos.

Neste cenário, as bases de dados e os $e$-books são de grande relevância, pois são fontes confiáveis que armazenam e disseminam informação científica selecionada e de qualidade aos pesquisadores. Com isso, observa-se o papel fundamental que as bibliotecas universitárias possuem como mediadoras de informação.

\subsection{BASE DE DADOS}

As bases de dados são definidas por Cunha (2001, p. 35) como "[...] a expressão utilizada para indicar a coleção de dados que serve de suporte a um sistema de recuperação de 
informações". Cendón (2002, p. 31) discorre que:

Bases de dados são arquivos de informação que, inicialmente, eram armazenados em computadores centrais e se tornavam acessíveis aos usuários em localizações remotas, via redes de comunicações. O aumento da capacidade dos meios de armazenagem magnéticos (como, por exemplo, os CD-ROMs) permitiu que as bases de dados passassem a se tornar também disponíveis localmente.

Existem bases de dados referenciais e as de texto integral. As primeiras contêm uma lista de registros bibliográficos, às vezes, contêm o resumo, as palavras-chave e a lista de referências utilizadas pelos autores, já as segundas possibilitam acesso ao texto completo. Ressaltase que as bases de dados variam em seu conteúdo, por exemplo, pode ser de periódicos, anais de eventos, dados estatísticos, patentes, normas técnicas, e-books, entre outros.

Conforme Santos e Silva (2017), "as bases de dados se tornaram peças-chave para a disseminação da informação produzida nas universidades, dando maior rapidez na divulgação de pesquisas científicas produzidas no mundo todo". No contexto acadêmico, para ter acesso a diversas bases de dados bibliográficas e as bases de dados em texto integral, as instituições precisam pagar por sua assinatura ou estar dentro dos requisitos exigidos pela Coordenação de Aperfeiçoamento de Pessoal de Nível Superior (CAPES) para ter acesso Portal de Periódicos, que:

[...] oferece acesso a textos completos disponíveis em mais de 37 mil publicações periódicas, internacionais e nacionais, e a diversas bases de dados que reúnem desde referências e resumos de trabalhos acadêmicos e científicos até normas técnicas, patentes, teses e dissertações dentre outros tipos de materiais, cobrindo todas as áreas do conhecimento (PORTAL DE PERÍODICOS CAPES, 2016).

O Portal de Periódicos da Capes além de alocar os materiais citados anteriormente, direciona os usuários às bases de dados das áreas de Ciências Agrárias; Ambientais; Biológicas; da Saúde; Exatas e da Terra; Humanas; Sociais Aplicadas; Engenharias; Linguística, Letras e Artes; e de áreas Multidisciplinares.

\subsection{LIVROS ELETRÔNICOS (E-BOOKS)}

$\mathrm{Na}$ sociedade contemporânea, mudanças significativas estão ocorrendo no cenário tecnológico. Eloy (2012) destaca que os suportes informacionais estão gradativamente estabelecendo-se no mercado editorial, tratam-se dos e-books (livros eletrônicos), e-readers (leitores eletrônicos portáteis) e tablets. O mercado está repleto de opções de acordo com gostos e necessidades.

Neste sentido, os livros eletrônicos ganham cada vez mais destaque nesta sociedade. Conforme Kama (2016, p. 38) "O livro eletrônico entra na seara dos novos meios de apreensão de informação que culminaram com a chegada das tecnologias da informação no século XX". Ele pode ser conceituado da seguinte forma:

O livro eletrônico é a denominação da espécie, da classe (ou gênero) de leitores eletrônicos (ereaders), que tenham o animus de mimetizar e expandir as funcionalidades de um livro tradicional e, portanto, com pelo menos um conteúdo informacional (obra) contido em seus dispositivos de memória; dessa forma, nesta espécie de leitor eletrônico é indissociável o conteúdo informacional (corpus misticum), em formato digital, com o dispositivo tecnológico (corpus mechanicum) que processa, exibe e permite a interação com o conteúdo informacional (DIAS; VIEIRA; SILVA, 2013. p. 11).

De acordo com Bufrem e Sorribas (2009), uma das vantagens do livro eletrônico em bibliotecas universitárias são as novas possibilidades de estudo, favorecendo a pesquisa. De forma complementar, Fenerick e Silva (2015, p. 10) mencionam que "[...] é indiscutível a agregação de e-books ao acervo das bibliotecas universitárias. $\mathrm{O}$ acesso simultâneo a obras digitais não limita o acesso apenas ao número de itens impressos que faz parte do acervo dessas bibliotecas, suprindo assim, as necessidades informacionais de uma quantidade maior de usuários."

Para Figueiredo (2016), existem vantagens e desvantagens na utilização dessas fontes. As vantagens são: facilidade de aquisição através da internet; possuir uma grande quantidade de livros num único dispositivo; possibilidade de consulta da mesma obra, ao mesmo tempo, por vários utilizadores; interatividade e utilização de recursos multimídia; acesso a links externos 
(complementado assim sua leitura); dimensão reduzida; facilidade de acesso ao livro em qualquer lugar; menor preço, além de ter $e$-books gratuitos; armazenamento em disco rígido ou dispositivo de leitura; possibilidade de fazer anotações e sublinhados; adaptabilidade aos leitores com necessidade especial.

As desvantagens são: leitura lenta e cansativa; não permite efetuar anotações pessoais; preço elevado dos dispositivos; pouca quantidade de exemplares em determinadas áreas do saber; crescente prática contra os direitos de autores; variedade de formatos, os diferentes tipos de formatos também constituem um entrave à leitura de e-books; dependência de plataformas e softwares; resistência aos hábitos de leitura digital; necessidade de ter um dispositivo de leitura, de uma bateria e de um carregador; e fragilidade.

Observa-se que há inúmeras vantagens e desvantagens no uso dos e-books, bem como ocorre com outros recursos digitais. Neste sentido, "As bibliotecas enfrentam um desafio na transição entre o tradicional e o digital, consequentemente, são necessárias adaptações e mudanças na forma como o bibliotecário realiza a gestão das unidades de informação" (FIGUEIREDO, 2016, p. 17).

A seguir os procedimentos metodológicos desta pesquisa serão apresentados.

\section{PROCEDIMENTOS METODOLÓGICOS}

A investigação possui caráter exploratório, que segundo Freitas e Prodanov (2013, p. 127) têm como finalidade proporcionar informações sobre o assunto investigado, porquanto, "[...] visa a proporcionar maior familiaridade com o problema, tornando-o explícito ou construindo hipóteses sobre ele". Também é utilizado o método comparativo, que "[...] procede pela investigação de indivíduos, classes, fenômenos ou fatos, com vistas a ressaltar as diferenças e as similaridades entre eles" (FREITAS; PRODANOV, 2013, p. 38). Neste sentido, tais formas de pesquisa são adequadas para conseguir alcançar os objetivos propostos.

$\mathrm{O}$ universo da pesquisa foi composto por duas bibliotecas universitárias localizadas no Estado do Espírito Santo (ES), sendo uma de caráter público e a outra de caráter privado, que estão localizadas na Região Metropolitana de Vitória, uma na cidade de Vitória e a outra em Vila
Velha.

Utilizou-se como instrumento de coleta de dados a entrevista semi-estruturada, que continha perguntas relacionadas às fontes de informação digitais, com ênfase nas bases de dados e nos $e$ books. Essa entrevista foi aplicada junto aos responsáveis pela biblioteca ou do setor de recursos informacionais. No primeiro caso, na biblioteca universitária caráter público, a entrevista foi realizada presencialmente e, no segundo, na biblioteca universitária de caráter privado, via internet, ambas no mês de novembro de 2016. Os participantes foram denominados como Participante 1 e Participante 2.

As questões do roteiro de entrevista foram organizadas em categorias de acordo com os objetivos estabelecidos, a saber: aquisição das fontes de informação digitais; disponibilização dos recursos informacionais, uso dos produtos e recursos informacionas e; atividades educacionais acerca dos processos informacionais.

Para realizar a análise, utilizou-se a forma qualitativa. Esse tipo de pesquisa, segundo Córdova e Silveira (2009, p. 31-32) “[...] não se preocupa com representatividade numérica [...] preocupa-se, portanto, com aspectos da realidade que não podem ser quantificados, centrando-se na compreensão e explicação da dinâmica das relações sociais". A seguir, encontram-se os resultados obtidos.

\section{RESULTADOS: APRESENTAÇÃO E DISCUSSÃO}

Conforme estabelecido na metodologia, os resultados foram organizados em categorias, possibilitando o agrupamento das questões conforme a temática, organizadas da seguinte forma: aquisição das fontes de informação digitais; disponibilização dos recursos digitais; uso dos produtos e recursos informacionais e; atividades educacionais acerca dos processos informacionais.

\subsection{AQUISIÇÃO DAS FONTES DE INFORMAÇÃO DIGITAIS}

No que tange à aquisição de recursos eletrônicos, buscou-se saber quais as bases de dados que as unidades de informação possuíam. Verificou-se que a biblioteca de caráter público possui acesso ao conteúdo integral do Portal de Periódicos Capes de forma gratuita, 
possibilitando o acesso a inúmeras bases de dados, com diversos tipos de materiais, artigos científicos, patentes, entre outros.

De acordo com o Participante 1, há também uma coleção próxima a dois mil títulos de $e$ books, nacionais e estrangeiros, adquiridos por compra perpétua ${ }^{1}$, da editora Elsevier. Esta biblioteca possui a assinatura de alguns bancos de dados que são renovadas anualmente, dentre elas estão: Academy Search Complete, RT Online, IEEE, Wire, Cambridge, Lexio, que faz a agregação dos editores Jorge Zahar, Senac-SP, Science Direct. Das editoras citadas, todas disponibilizam somente recursos em formato digital, exceto a Jorge Zahar e Senac-SP, que trabalham com livros digitais e impressos.

A biblioteca universitária de caráter privado possui acesso às bases de dados UpToDate; a MedicinaNET; o Portal Médico do Brasil, que dá acesso, além de artigos na área da saúde, ferramentas como o Med Calc 3000 e; a ACP Medicine, bem como conteúdos internacionais traduzidos com exclusividade para o uso da universidade. Estas bases são mantidas através de assinatura (Participante 2).

Essa biblioteca também possui acesso às bases de dados de caráter restrito do Portal de Periódicos da CAPES. Conforme informações fornecidas pelo participante 2 "O referido acesso foi disponibilizado pela CAPES em reconhecimento ao seu esforço no que tange ao desenvolvimento da pesquisa científica e à manutenção de cursos de Pós-Graduação Stricto Sensu no país".

\subsection{DISPONIBILIZAÇÃO DOS RECURSOS DIGITAIS}

Esta categoria abrange quatro questões referentes ao processo de disponibilização das fontes de informação digitais, com as seguintes temáticas: identificação das fontes, forma de acesso aos usuários, os meios de divulgação e disponibilização dos recursos.

Nesta questão, teve-se a pretensão de verificar quais são as fontes de informação digitais disponibilizadas pelas bibliotecas. A biblioteca universitária de caráter público possibilita acesso

\footnotetext{
1 A compra ou aquisição perpetua de e-books "[...] consiste no pagamento único ao fornecedor para adquirir o material desejado e ele, em teoria, será mantido em poder da biblioteca perpetuamente" (GOMES, ZATTAR, 2016, p. 68).
}

às bases de dados e aos e-books; na biblioteca universitária de caráter privado é oferecido acesso às bases de dados, conforme Participante 2.

Complementarmente, buscou-se saber qual a forma de acesso às bases de dados pelos usuários. O Participante 1 relatou que, em um primeiro momento, os usuários tomam ciência das obras, recursos e serviços, sejam graduandos, pós-graduandos, servidores, técnicos ou docentes. Posteriormente, podem acessar as bases de dados através de qualquer computador da universidade vinculado à rede da instituição e aos laboratórios de informática. Além disso, também existe a possibilidade de acesso de forma remota (da residência dos usuários, por exemplo), conforme é explicitado pelo Participante 1:

[...] quem tem vínculo com a universidade, independente do grau de vínculo, se é graduação, pós, servidor, técnico ou docente, tem a possibilidade de fazer o acesso remoto [...]. De casa, ele precisa fazer uma configuração no navegador por meio da proxy de rede que, na realidade, se puxa uma extensão da rede [ ] para a casa do usuário. E ele pode acessar igualmente se estivesse aqui dentro da universidade.

O participante 2 mencionou que "[...] os acessos são restritos aos computadores da universidade". Contudo, para os alunos de mestrado, doutorado e professores são liberados o acesso remoto. Ambas as instituições agem da mesma forma na disponibilização destes materiais. De modo geral, os usuários de ambas as universidades podem acessar as bases de dados e os e-books ${ }^{2}$ através dos computadores dessas instituições, e por acesso remoto a determinados tipos de usuários com vínculo com a universidade.

Ainda referente às bases de dados, procurouse verificar a forma de divulgação aos seus usuários. A biblioteca de caráter público sempre busca divulgar os seus serviços e novas aquisições pelo site da biblioteca - através de banners no site - indicando o acesso às obras que a biblioteca possui. Além disso, alguns serviços são divulgados através do "Jornal Informa", na rede social utilizada pela instituição "Facebook", e em alguns casos, por correio eletrônico. Neste

\footnotetext{
${ }^{2}$ Os $e$-books podem ser utilizados no caso biblioteca da universidade de caráter público.
} 
último, é enviado um e-mail para os Centros Acadêmicos (CAs) que, por sua vez, repassam aos alunos de seus respectivos cursos, conforme Participante 1. Já a Biblioteca de caráter privado divulga suas bases de dados através da página da biblioteca no site da instituição, de folders e informativos dentro da unidade de informação, de acordo com o Participante 2. Ambas as instituições promovem ações no sentido de divulgar os materiais adquiridos, com a finalidade de que os usuários conheçam suas fontes e recursos informacionais e, assim, façam uso dos mesmos.

Em uma questão buscava identificar se os $e$ books eram disponibilizados aos usuários, caso houvesse na biblioteca. De acordo com Fenerick e Silva (2015, p. 7), “A inserção do e-book [...] nos acervos de bibliotecas universitárias gera uma série de questões, principalmente, no que se refere à sua política de aquisição que se difere do modelo tradicional."

Apenas o Participante 1 mencionou diretamente que disponibiliza este tipo de material, entretanto, pode-se considerar a biblioteca da instituição privada também possui acesso aos $e$-books, vistos que estão inclusos no Portal de Periódicos da CAPES. Além disso, especificamente, no site da biblioteca da universidade pública, há um banner que, ao clicar, o usuário é direcionado aos livros digitais de cada editora. Neste sentido, observa-se que:

Cada editor tem um modelo de negócio [...]. Tem uns, por exemplo, os livros nacionais, que são consultados apenas na tela. Não se consegue fazer impressão, download, nada. Outros, por exemplo, os livros da editora Elsevier, você consegue imprimir o livro todo, da primeira à última página, como também os editores Cambridge, Wire, sem problema nenhum (Participante 1).

Salienta-se que o acesso aos e-books pode ocorrer por meio de outros aparatos tecnológicos, tais como os tablets, e-readers e celulares. Porém, a aquisição e disponibilização deste tipo de material pelas bibliotecas universitárias ainda é algo complexo. Para Costa e Cunha (2015, p. 18), a "aquisição de livros eletrônicos para uma biblioteca é algo confuso e com inúmeros detalhes técnicos (hardware, software, financeiros e direitos autorais, entre outros)". Entretanto, é importante mencionar que "[...] o uso e as vendas de livros eletrônicos no mundo possuem, sim, uma tendência presente e futura no seu crescimento" (KAMA, 2016, p. 44). O Participante 1 relato que não é feito empréstimos por recursos móveis.

Constata-se que ambas as bibliotecas possuem acesso às fontes de informação digitais. Entretanto, infere-se com base na fala do Participante 1, que a biblioteca da universidade pública têm maior clareza da importância de tais livros como fontes de informação essenciais para o estudo e pesquisa, também observa-se, que no site institucional desta biblioteca, os e-books estão destacados.

A seguir buscou-se verificar aspectos referentes ao uso dos produtos e recursos informacionais pelos usuários.

\subsection{USO DOS PRODUTOS E RECURSOS INFORMACIONAIS}

Esta categoria é composta por uma questão, que visava identificar fatores referentes às dificuldades dos usuários no uso das bases de dados, conforme Cuenca (1999, p. 294):

\begin{abstract}
Além do desconhecimento, dificuldades como a existência de várias interfaces de busca para o acesso às bases de dados, tempo de busca, campos disponíveis para recuperação e a nãofamiliarização com o vocabulário especializado da área são colocados como motivo da nãoutilização do acesso às bases automatizadas pelos usuários de buscas informatizadas.
\end{abstract}

Apesar desta citação de Cuenca ser da década de 1990, compreende-se que nos dias de hoje essas dificuldades de manuseio das bases de dados pelos usuários ainda estão presentes. A partir dos resultados desta pesquisa, foi constatado que em ambas as unidades de informação os usuários apresentam algumas dificuldades de acesso e recuperação da informação nestas fontes e, algumas vezes, certa resistência em sua utilização. O participante 1 afirma que "[...[ a literatura mostra que apesar dessa geração ser muito integrada às tecnologias de informação [...] existe muita dificuldade na recuperação da informação". O participante 2 atesta que "É natural que num primeiro momento haja uma dificuldade, visto que esse tipo de recurso não é comum em escolas de ensino de base". Complementando essas constatações, Mesquita et al. (2005) discorre que muitos estudos afirmam que o usuário novato pode apresentar algumas dificuldades quando começa a realizar buscas em bases de dados. 
Uma das formas para enfrentar as dificuldades apresentadas pelos usuários é realizar atividades de formação de usuários, apresentando a biblioteca, seus produtos e serviços, com enfoque nas fontes de informação eletrônicas, possibilitando o desenvolvimento habilidades informacionais referentes aos processos de seleção, busca, avaliação e uso ético da informação. Desta forma, os bibliotecários disseminam os recursos da biblioteca e contribuem nas ações de mediação e apropriação da informação (NUNES, CARVALHO, 2016).

\subsection{FORMAÇÃO DE USUÁRIOS}

Existem variados termos utilizados para representar as atividades educacionais acerca das fontes de informação realizadas nas unidades de informação, cada um com um foco específico, que variam desde a educação de usuário (atividades mais tradicionais realizadas acerca dos sistemas de informação) até a competência em informação. Esta última tem enfoque nos processos informacionais de seleção, busca, uso, avaliação e comunicação da informação de maneira ética. A tarefa essencial na formação de usuários é informar aos usuários os recursos informacionais existentes nas bibliotecas e em outros ambientes (presenciais ou virtuais), ensiná-los a utilizar e tirar o máximo de proveito dos mesmos, de forma que se tornem autônomos nos processos de busca e uso da informação (MATA, ALCARÁ, 2016).

Neste sentido, procurou-se identificar se essas instituições realizam algum tipo de atividade de formação de usuários. A biblioteca da universidade de caráter público possui dois programas de capacitação, um voltado para o treinamento dos bibliotecários da instituição, chamado "Núcleo", que visa capacitar os profissionais bibliotecários para que possam oferecer treinamentos aos seus usuários (Participante 1).

A outra capacitação é direcionada aos seus usuários, que foi denominado de "Programa de Desenvolvimento de Competência Informacional em Ambiente Virtual" (PDCIAVI). Este programa é realizado através de uma programação semestral que tem como públicoalvo os estudantes da instituição, principalmente, aqueles de pós-graduação, pois são estes que utilizam com maior frequência artigos para o desenvolvimento de suas dissertações e teses. É oferecido em forma de oficinas, que ocorrem duas vezes por semana com temática voltada para o uso dos recursos bibliográficos digitais. Além do que, no início de cada semestre, na recepção de calouros, os bibliotecários apresentam de forma rápida e superficial tais recursos aos ingressantes, a fim de mostrar a existência dessas fontes de informação (Participante 1). No site da instituição, foi possível encontrar a temática das oficinas, a saber: a) Uso do catálogo do sistema integrado de bibliotecas; b) Fontes de informação on-line; c) Portal de Periódicos Capes; d) Gerenciador bibliográfico EndNote Web; e) Indicadores de Impacto Científico. Também são oferecidas visitas guiadas e no site institucional tem tutoriais para uso de determinadas fontes.

A biblioteca da universidade de caráter privado também oferece atividades de formação aos seus usuários internos para a utilização das bases de dados. Existe parceria com professores da instituição que levam os seus alunos à biblioteca para um treinamento em grupo com toda a turma, além das orientações individuais que ocorrem diariamente no serviço de referência (Participante 2). No site da instituição consta que também são realizadas visitas orientadas ao grupo de estudantes.

De modo geral, todas as atividades educacionais realizadas no âmbito da biblioteca universitária são importantes, desde a visita guiada aos programas de competência em informação. Esses serviços possibilitam aos indivíduos conhecerem as bibliotecas, recursos e produtos ali disponíveis, bem como atividades ligadas aos processos informacionais de busca e uso da informação em variados ambientes.

Consideram-se que para que as bibliotecas universitárias alcancem seus objetivos com excelência é necessário que acompanhem as inovações tecnológicas, propiciando aos seus usuários o acesso a variados tipos de fontes de informação, desde as convencionais às fontes digitais, bem como atividades de formação para que eles aprendam a utilizá-las.

\section{CONSIDERAÇÕES FINAIS}

As bibliotecas universitárias brasileiras passaram por várias mudanças significativas. A presença de novas tecnologias e de novos perfis de usuários demanda adaptação aos novos tempos para continuar a desenvolver seu papel, dentro das universidades e na sociedade da informação, oferecendo recursos, produtos e 
serviços que satisfaçam as necessidades dos usuários.

Essas bibliotecas são consideradas como espaços de conhecimento e de aprendizagem, devendo possibilitar o acesso, disseminação e uso de diversos tipos de fontes de informação impressas e digitais, de modo que auxiliem a universidade a alcançar seus objetivos no que se refere ao tripé ensino, pesquisa e extensão.

Desta forma, esta pesquisa buscou analisar as fontes de informação digitais disponibilizadas por duas bibliotecas universitárias do Estado do Espírito Santo, visto que contribuem com a formação de recursos humanos, com atividades de pesquisa e de extensão que, consequentemente, promove o desenvolvimento educacional, cultural, tecnológico e econômico do Estado.

Analisando a preparação do profissional da informação neste contexto, acredita-se que ele possa enfrentar dificuldades, principalmente, no processo de aquisição de tais fontes de informação. Porém, sempre há a necessidade de se adaptar às mudanças, principalmente, as que trazem facilidades e melhorias aos usuários, porquanto existem grandes vantagens no uso dessas fontes e ferramentas, sendo importante torná-las acessíveis nas unidades de informação. Conforme Reis, Blattmann e Reis (2011, p. 2), uma das preocupações dos bibliotecários é "[...] como, onde, quando, qual tipo e porque ofertar serviços e produto on-line em atividades de ensino e pesquisa."

Conclui-se que tais bibliotecas vêm oferecendo acesso e divulgando os diversos recursos e fontes de informação digitais, com ênfase nas bases de dados. Também foi observado, por meio do relato dos participantes, que a utilização e a aceitação dos recursos digitais por parte dos usuários têm crescido e, que, segundo estes, esta é uma tendência. No que se referem aos $e$-books, estes estão disponíveis por meio das bases de dados nas duas bibliotecas e, em um delas, também, está incluso em seu site institucional, ressaltando-se que não houve aquisição de tablets e/ou outros dispositivos por tais unidades de informação.

Também são oferecidas atividades de formação de usuários, contudo, possuem características diferenciadas. Na biblioteca da universidade pública existe um programa com diversos módulos (visita guiada, tutoriais online, fontes de informação geral e especializada, gerenciador bibliográfico e indicadores de impacto científico) oferecido pelos bibliotecários para que os estudantes e professores possam aprender utilizar e ter maior aproveitando dos recursos informacionais ali existente e fora da instituição. Por sua vez, na biblioteca da universidade de caráter privado, oferecem-se visitas guiadas e treinamento em bases de dados.

A maior diferenciação entre estas bibliotecas está nas atividades de formação de usuários, visto que a biblioteca de caráter público abrange, além de atividades de busca e recuperação da informação em bases de dados, o emprego de diversos recursos informacionais. Tais atividades são fundamentais para que os usuários adquiram conhecimento da existência e sejam preparados para o seu uso.

Recomenda-se que as fontes de informação digitais, tais como os livros eletrônicos, sejam explorados pelas universidades de ambas as instituições, considerando-se sua importância e ampla divulgação no contexto da sociedade contemporânea. Conforme Fenerick e Silva (2015, p. 12), "o acesso aos e-books pode contribuir para a formação do estudante bem como pode fortalecer as relações de internacionalização de estudos". 


\title{
THE DIGITAL INFORMATION RESOURCES IN UNIVERSITY LIBRARIES: A STUDY FROM PUBLIC AND PRIVATE UNIVERSITIES IN THE STATE OF ESPÍRITO SANTO (ES)
}

\begin{abstract}
University libraries seek to follow these innovations to facilitate to their users the access to information by offering them different features, services and products, including digital information resources. In this regard, this study investigates the digital resources available to users of two public and private university libraries in the state of Espirito Santo (ES). The specific objectives of this paper are: to identify the digital resources acquired by libraries; how they are made available; if Libraries offer user training activities related to the use of these resources. The investigation aims to show possible differences between public and private institutional environments. For that, exploratory research and qualitative analysis of the results were carried out. The results show that these libraries are acquiring digital information resources making them available to the academic community and carrying out user training activities to promote the use of these resources among library users.
\end{abstract}

Keywords: University library. Digital Information resources. Database. Electronic Books.

\section{REFERÊNCIAS}

ALCARÁ, A. R.; SILVA, T., TOMAÉL, M. I. E. Fontes de informação na internet: critérios de qualidade. In: TOMAÉL, M. I.; VALENTIM, M. L. P. Fontes de informação na internet. Londrina, EDUEL, 2008.

ALMEIDA, C. C. Portais verticais. In: TOMAÉL, M. I.; VALENTIM, M. L. P. Fontes de informação na internet. Londrina, EDUEL, 2004. p. $57-86$

BRASIL. Lei 9.394, de 20 de dezembro de 1996. Estabelece as diretrizes e bases da educação nacional. Diário Oficial da União, Brasília, DF, 20 de dez. de 1996. Disponível em: http://www.planalto.gov.br/ccivil_03/LEIS/19394. htm. Acesso em: 30 mar. 2017

BUFREM, L. S.; SORRIBAS, T. V. Práticas de leitura em meio eletrônico. ETD, v. 11, n. 1, p. 298-326, jul./dez. 2009. Disponível em: <http://bogliolo.eci.ufmg.br>. Acesso em: 30 jun. 2017

CENDÓN, B. V. Base de dados de informação para negócios. Ciência da Informação, Brasília, v. 31, n. 2, p. 30-43, maio/ago. 2002.

CÓRDOVA, F. P.; SILVEIRA, D. T. Métodos de pesquisa. Porto Alegre: Editora da UFRGS, 2009.
COSTA, R. P.; CUNHA, M. B. Modelo de negócios de livros eletrônicos para

bibliotecas. Informação e Sociedade, João Pessoa, v. 25, n. 3, p. 7-19, set./dez. 2015. Disponível em: <http://www.ies.ufpb.br/ojs/index.php/ies/article/ view/26945>. Acesso em: 15 jun. 2017.

CUENCA, A. M. B. O usuário final da busca informatizada: avaliação da capacitação no acesso a bases de dados em biblioteca acadêmica. Ciência da Informação, Brasília, v. 28, n. 3, p. 293-301, set./dez. 1999. Disponível em: $<$ http://www.scielo.br/scielo.php?script=sci_artte xt\&pid=S0100-19651999000300007>. Acesso em: 26 fev. 2017.

CUNHA, M. B. Para saber mais: fontes de informação. Brasília, DF: Briquet de Lemos, 2001.

DIAS, C. A.; VIEIRA, A. A. N.; SILVA, A. L. A. Em busca de uma definição para o livro eletrônico: o conteúdo informacional e o suporte físico como elementos indissociáveis. In: ENCONTRO NACIONAL DE PESQUISA EM CIÊNCIA DA INFORMAÇÃO, 14, 2013, Florianópolis. Anais... Florianópolis: ANCIB, 2013. Disponível em: < http://eprints.rclis.org/20904/1/Em\%20busca\%20 de\%20uma\%20defini\%C3\%A7\%C3\%A3o\%20pa 
ra\%20o\%20livro\%20eletr\%C3\%B4nico.pdf Acesso em: 18 jun. 2017

DIAS, M. M. K. et al. Capacitação do bibliotecário como mediador do aprendizado no uso de fontes de informação. Revista Digital de Biblioteconomia e Ciência da Informação, Campinas, v. 2, n. 1, p. 1-16, jul./dez. 2004. Disponível em: <http://eprints.rclis.org/6457/>. Acesso em: 12 out. 2016.

\section{ELOY, R. Z. O Bibliotecário e a leitura}

conectada: competência informacional digital na era dos e-books, e-readers e tablets. São Paulo: PerSe, 2012.

FENERICK, G. M. P.; SILVA, M. R. Percepção dos estudantes quanto ao uso do acervo de ebooks de uma biblioteca universitária. Biblos: Revista do Instituto de Ciências Humanas e da Informação, v. 29, n. 2, p. 5-23, 2015.

FIGUEIREDO, M. M. R. O papel dos ebooks nas bibliotecas universitárias: o caso da Universidade de Aveiro. 2016. 175 f. Dissertação (Mestrado em Ciência da Informação) Faculdade de Letras da Universidade de Coimbra, Universidade de Coimbra, 2016.

FREITAS, E. C.; PRODANOV, C. C.

Metodologia do trabalho científico: métodos e técnicas da pesquisa e do trabalho acadêmico. 2 . ed. Novo Hamburgo, RS: Feevale, 2013.

GOMES, J. S.; ZATTAR, M. Modelo de negócio para aquisição de livros eletrônicos. Revista Conhecimento em Ação, Rio de Janeiro, v. 1, n. 1, jan./jun. 2016.

KAMA, A. F. L. F. Livros, bibliotecas universitárias e livros eletrônicos: aspectos e conseqüências de um novo suporte de escrita. 2016, 122. Dissertação (Mestrado em Ciência da Informação) - Programa de Pós-Graduação em Ciência da Informação, Universidade de Brasília, 2016.

MATA, M. L.; ALCARÁ, A. R. Análise das práticas educacionais dos bibliotecários em bibliotecas universitárias com enfoque na educação de usuários e na competência em informação. In: ENCONTRO NACIONAL DE PESQUISA EM CIÊNCIA DA INFORMAÇÃO, 17., Salvador., 2016. Anais eletrônicos...
>. Salvador, BA: ANCIB, 2016. Disponível em: $<$ http://basessibi.c3sl.ufpr.br/brapci/index.php/arti cle/view/0000021895/2695545d96351c3ca7deda 33023ff70a >. Acesso em: 25 jun. 2017.

MESQUITA, R. M. A. et al. Satisfação de usuários no uso de base de dados bibliográfica: um estudo de caso. In: ENCONTRO NACIONAL DE PESQUISA EM CIÊNCIA DA INFORMAÇÃO, 6., 2005, Florianópolis, SC. Anais eletrônicos... Florianópolis, SC: ANCIB, $2006 . \quad$ Disponível em: <http://enancib.ibict.br/index.php/enancib/vienan cib/paper/view/1795/936>. Acesso em: 15 mar. 2017.

MIRANDA, A. C. C. Desenvolvimento de coleções em bibliotecas universitárias. Revista Digital de Biblioteconomia e Ciência da Informação, Campinas, v. 4, n. 2, p. 1-19, já./jn. 2007.

MUELLER, S. P. M. A ciência, o sistema de comunicação científica e a literatura científica. In: CAMPELLO, Bernadete Santos; CENDÓN, Beatriz Valadares;

KREMER, Jeannette (Orgs.). Fontes de informação para pesquisadores e profissionais. Belo Horizonte: UFMG, 2007. p. 21-31

NUNES, M. S. C.; CARVALHO, K. As bibliotecas universitárias em perspectiva histórica: a caminho do desenvolvimento durável. Perspectiva em Ciência da Informação, v. 21, n. 1, p. 173-193, jan./mar. 2016.

PORTAL DE PERIÓDICOS CAPES. 2016. Disponível em: <http://www-periodicos-capesgov-

br.ez43.periodicos.capes.gov.br/index.php?option $=$ com_phome \&Itemid $=68 \&>$ Acesso em: 15 jun. 2017.

REIS, M. M. O., BLATTMANN, U; REIS, V. Acesso e uso de fontes de informação on-line no ambiente de ensino e pesquisa. In: SEMINÁRIO NACIONAL DE BIBLIOTECAS UNIVERSITÁRIAS, 13., 2004, Natal. Anais eletrônicos... Natal, RN: Universidade Federal do Rio Grande do Norte, 2004. Disponível em: < http://www.oocities.org/ublattmann/papers/acesso _uso_fontes.pdf>. Acesso em 06 jul. 2017. 
RODRIGUES, C.; BLATTMANN, U. Uso das fontes de informação para a geração de conhecimento organizacional. Perspectivas em Gestão \& Conhecimento, João Pessoa, v. 1, n. 2, p. 43-58, jul./dez. 2011. Disponível em: <http://periodicos.ufpb.br/ojs2/index.php/pgc/arti cle/view/9999/6922>. Acesso em: 15 jun. 2017.

SANTOS, S. A.; SILVA, R. C. Acesso das bases de dados nas universidades federais: o caso da Universidade Federal de Santa Maria - Campus Frederico Westphalen. Biblionline, João Pessoa, v. 13, n. 2, jul./dez. 2017.

SILVA, T. E.; TOMAÉL, M. I. Fontes de informação na internet: a literatura em evidência. In: TOMAÉL, M. I.; VALENTIM, M. L. P.
(Orgs.). Avaliação de fontes de informação na internet. Londrina, PR: Eduel, 2004. p. 19-40.

SILVEIRA, M. A. A. Rede de textos científicos: um estudo sob a ótica da institucionalização da Ciência da Informação no Brasil. 2008. 133 f. Dissertação (Mestrado em Ciência da Informação) - Programa de Pós-Graduação, Pontifícia Universidade Católica de Campinas, Campinas, 2008.

SOUTO, L. F. Informação seletiva, mediação e tecnologia: a evolução dos serviços de disseminação seletiva de informações. Rio de Janeiro: Interciência, 2010.

UNESCO. Declaração mundial sobre educação superior. Tradução de Amos Nascimento. Piracicaba: UNIMEP, 1998. 